\title{
Doctoral Dissertations by Publication: Building Scholarly Capacity Whilst Advancing New Knowledge in the Discipline of Nursing
}

\author{
Karen Francis \\ School of Nursing \& Midwifery, \\ Monash University, \\ Gippsland Campus, Churchill, VIC, \\ Australia
}

\author{
Jane Mills \\ School of Nursing, Midwifery \\ and Nutrition, James Cook \\ University, Cairns Campus, \\ Smithfield. QLD, Australia
}

Karen.francis@med.monash.edu.au

Jane.mills@jcu.edu.au

\author{
Ysanne Chapman and Melanie Birks \\ School of Nursing \& Midwifery, Monash University, Gippsland \\ Campus, Churchill, VIC, Australia
}

\section{Ysanne.Chapman@med.monash.edu.au Melanie.Birks@med.monash.edu.au}

\begin{abstract} therefore is an important strategy to support this endeavour.

Material published as part of this publication, either on-line or in print, is copyrighted by the Informing Science Institute. Permission to make digital or paper copy of part or all of these works for personal or classroom use is granted without fee provided that the copies are not made or distributed for profit or commercial advantage AND that copies 1) bear this notice in full and 2) give the full citation on the first page. It is permissible to abstract these works so long as credit is given. To copy in all other cases or to republish or to post on a server or to redistribute to lists requires specific permission and payment of a fee. Contact Publisher@InformingScience.org to request redistribution permission.
\end{abstract}

Internationally universities are increasingly challenged by government and industry to boost their research profile. Undertaking successful research studies is a means of generating income while enhancing the credibility of both institutions and individual academic staff. Research training

Traditionally, the process of research training culminates in the completion of a doctoral qualification. Undertaking doctoral studies requires candidates to commit to an extensive period of indenture during which they develop their knowledge about a particular methodology, refine skills in using research methods, and produce research findings in the form of a dissertation. A key part of this process is developing skills in writing for publication and the dissemination of their doctoral research findings. We argue that using a traditional approach to the production of a doctoral dissertation develops student's knowledge and skills in conducting an independent piece of research. However, the production of a traditional thesis does not focus strongly enough on developing the important skills of writing for publication and knowing how to effectively and strategically disseminate research findings.
Choosing to submit a doctoral dissertation by publication or partial publication provides candidates with the opportunity to complete research training and produce an authoritative research report, while at the same time developing skills in publishing journal articles and other manifests. Producing a dissertation by partial or full publication also opens the work up to independent scrutiny at vari- 
ous points during the candidate's research training which strengthens the final results.

Key Words: doctoral studies, publication, partial publication, $\mathrm{PhD}$, dissertation, thesis

\section{Introduction}

For too many years, important research findings in the discipline of nursing and midwifery have languished on the shelves of libraries, literally hidebound by the format used in the production of a traditional doctoral dissertation. For the past five years, an Australian University's School of Nursing and Midwifery has actively encouraged doctoral candidates to undertake their research training with a goal of submitting their doctoral dissertation by publication or partial publication. The rationale for this is multidimensional; however the primary driver is teaching doctoral candidates how to write for publication and the strategic dissemination of research findings. Other important considerations are: opening up the student's work for independent critique during the process of research training; the professional responsibility that universities have to add to the body of nursing and midwifery knowledge; increasing clinician's access to evidence for practice; raising awareness with industry and government about issues of importance for nurses and midwives; and, potentially, providing strategies for action through recommendations arising from doctoral research. In order to lose the reputation of living in an ivory tower, the academy has to be proactive in connecting research findings to practice and policy. We believe one way of achieving this is by encouraging the production of doctoral dissertations by publication or partial publication.

Undertaking a PhD is a major life commitment (Lee, 2009; Phillips \& Pugh, 1994) but it is not necessarily the pinnacle of an academic career, with an increasing number of nurses and midwives from a variety of backgrounds enrolling in doctoral programs. Enrolling in a doctoral program is not a decision taken lightly, as the amount of time and energy invested in completing the requirements for the awarding of this degree result in perhaps the most taxing of all study regimes (Smith, 2000).

The traditional doctoral dissertation and a doctoral dissertation by publication share common goals. In both cases, candidates identify a topic of interest, isolate a research question, decide on an appropriate research design, collect, analyse and interpret data, situate the new knowledge generated from the study within the broader literature, and offer recommendations for change and future research (Clare \& Stevens, 2003). The difference between these two approaches lies in the structure and presentation of the doctoral dissertation and in the impact of the research. A traditional doctoral dissertation is approximately 100,000 words detailing the study from conceptualisation to completion. Doctoral dissertation by publication achieves the same goals, together with the added outcome of tangible scholarly additions to the contemporary body of knowledge about nursing and midwifery generated during the period of candidature. This paper will examine the advantages and disadvantages of undertaking research training that produces a doctoral dissertation by full or partial publication. In addition, strategies to support candidates in this process will be discussed using the authors' experiences to illustrate key points.

\section{Advantages and Disadvantages of Doctoral Dissertation by Publication}

One of the criticisms of undertaking traditional doctoral studies has been the limited contribution of these studies to contemporary understanding (Steele, 2008). The rigour of the studies is not in question, rather the lack of enthusiasm of doctoral candidates following successful completion of their studies to draft and submit manuscripts for broad dissemination. Barriers to the publication of dissertation findings identified in a study by Timmons and Park (2008) were: a lack of confidence that findings were of a high enough quality; lack of support and guidance from supervisors 
when manuscripts are rejected; the need for practical skills development in learning how to write for publication; publishing is not a priority for some candidates; saturation and a sense of anticlimax post submission; and a shortage of time.

Adopting a full or partial publication approach to producing a doctoral dissertation ensures that the knowledge generated from doctoral research studies is disseminated. Moreover, this approach is a useful method to encourage completion. Chipman (1998) highlighted that in some university departments half of all research students fail to complete their course of study. Students who publish throughout their candidature receive ongoing peer review, enhance their writing skills, and are scholastically affirmed as manuscripts are accepted for publication. Publishing throughout candidature offers novice researchers the opportunity to test novel ideas, encourages enhancement of their writing skills, and provides a mechanism for showcasing expertise. The intent of this approach is for higher degree research students to increase dissemination of research findings while developing the link between expected pedagogical outcomes and reality. Kamler (2008) describes the pedagogical rationale supporting $\mathrm{PhD}$ by publication. She suggests that traditional $\mathrm{PhD}$ examination does not assess candidate's capacity to contribute to scholarship, a skill she maintains is an indicator of future scholarly activity. The $\mathrm{PhD}$ by publication heralds the relationship between the initial research training and future scholarship capacity as students learn how to write for publication throughout their candidature (Kamler, 2008). It also encourages publication of methodological papers that describe the adaptation and use of particular methods in various contexts. Building a publication track record throughout candidature can also be very advantageous for researchers who are planning to undertake post-doctoral research programs. Publication in a variety of referred journals, including those with a measured impact factor, increases the chance of new graduates being awarded a competitive grant, in addition to increasing their profile in a speciality area.

There are arguments presented against writing several publications from a doctoral dissertation (Morse, 2005; Webb, 2008) although several of these have been tempered of late as doctoral dissertation by publication is becoming an accepted practice. Morse (2005) suggests that the practice emanated from the 'hard science' group, as publication of small sections of data analyses is more fitting to quantitative data. Both Morse (2005) and Webb (2008) resoundingly disagree with the practice of 'salami slicing', a term used to describe the publication of qualitative data in small single sections, disregarding the analysis as a whole. Doctoral dissertation by publication, however, does not necessarily follow this practice. Rather, several meaningful and informative publications are likely to emerge from a research project, such as discussion and critique of methodology, explanation of new or innovative methods, and a discursive literature review. We agree that unnecessary dissection of data sets is to be avoided and suggest that creative approaches to data dissemination be employed when publishing findings and associated discussion so the concept of holism is not sacrificed.

A further argument purported against producing multiple articles from one research study is that of copyright (Webb, 2008). Copyright can be a messy issue and should be discussed with publishers prior to submission of an article, especially if it is the intention of the writer to post other articles about the same research study with other publishers. Some publishers agree that parts of the original article can be used without amendment or change in other publications (Webb, 2008); however, it is best to seek advice before proceeding with signing copyright forms or refer to the International Committee of Medical Journal Editors (2008) requirements that are freely available on the Internet. A summary of the advantages and disadvantages of each of these modes of production is provided in Table 1. 
Table 1: Advantages and Disadvantages of Modes of Dissertation Production

\begin{tabular}{|c|c|c|}
\hline & Advantages & Disadvantages \\
\hline \multirow[t]{5}{*}{$\begin{array}{l}\text { Traditional } \\
\text { dissertation }\end{array}$} & $\begin{array}{l}\text { Less scrutiny of writing means } \\
\text { that writing of the dissertation } \\
\text { may progress more quickly }\end{array}$ & $\begin{array}{l}\text { Low levels of confidence in their research } \\
\text { findings exhibited by candidates }\end{array}$ \\
\hline & $\begin{array}{l}\text { Traditional dissertation more ac- } \\
\text { ceptable to some examiners }\end{array}$ & $\begin{array}{l}\text { Supervisors providing inadequate mentoring } \\
\text { post submission to develop candidate's skills } \\
\text { at writing for publication }\end{array}$ \\
\hline & & $\begin{array}{l}\text { 'Post dissertation burnout' that results in } \\
\text { candidates producing few journal publica- } \\
\text { tions }\end{array}$ \\
\hline & $\begin{array}{l}\text { Analysis is presented as a singular } \\
\text { piece of work }\end{array}$ & $\begin{array}{l}\text { Time constraints post dissertation submis- } \\
\text { sion as candidates move on to new positions } \\
\text { resulting in few journal publications }\end{array}$ \\
\hline & & $\begin{array}{l}\text { Little encouragement to publish during the } \\
\text { process of candidature }\end{array}$ \\
\hline \multirow[t]{6}{*}{$\begin{array}{l}\text { Dissertation } \\
\text { by publica- } \\
\text { tion }\end{array}$} & $\begin{array}{l}\text { Continuous mentoring to guide } \\
\text { candidates in writing for publica- } \\
\text { tion } \\
\text { Candidates become skilled in } \\
\text { crafting manuscripts for publica- } \\
\text { tion }\end{array}$ & $\begin{array}{l}\text { Lack of experience in supervising disserta- } \\
\text { tion by publication can result in poor direc- } \\
\text { tion and result in lack of rigor and clear pol- } \\
\text { icy guidelines }\end{array}$ \\
\hline & $\begin{array}{l}\text { Independent feedback from res- } \\
\text { pected authorities on the progress } \\
\text { of the candidates work }\end{array}$ & $\begin{array}{l}\text { Long publication timelines for some journals } \\
\text { can be discouraging for candidates }\end{array}$ \\
\hline & $\begin{array}{l}\text { Evidence generated by candidates } \\
\text { is disseminated broadly from the } \\
\text { commencement of candidature }\end{array}$ & $\begin{array}{l}\text { Examiners who are unfamiliar with doctoral } \\
\text { dissertation by publication may provide un- } \\
\text { fair critique }\end{array}$ \\
\hline & $\begin{array}{l}\text { Increased potential for candidates } \\
\text { to complete their research training }\end{array}$ & $\begin{array}{l}\text { Potential for data fragmentation ('salami } \\
\text { slicing') and multiple data publication if re- } \\
\text { porting of results is inappropriately managed }\end{array}$ \\
\hline & $\begin{array}{l}\text { Candidates can test novel ideas } \\
\text { and promote their disciplinary } \\
\text { expertise }\end{array}$ & \\
\hline & $\begin{array}{l}\text { Development of a publication } \\
\text { track record that can be advanta- } \\
\text { geous in future career develop- } \\
\text { ment } \\
\text { Candidates become discerning } \\
\text { about where they publish }\end{array}$ & \\
\hline
\end{tabular}




\section{Supervisors as Writing Mentors}

The notion of novice academics creating mentoring relationships with more experienced scholars in order to support them during the process of learning to write for publication is very popular in the United States of America (Anders \& Monsivais, 2006; Morrison-Beedy, Aronowitz, Dyne, \& Mkandawire, 2001; Records \& Emerson, 2003; Wills \& Kaiser, 2002). An example of this is one American university where a part-time writing coach was employed to support and facilitate faculty members in writing for publication (Baldwin \& Chandler, 2002).

In Australia and New Zealand, little has been written about the development of nursing and midwifery scholarship through publication. Crookes (2002), in a review of the literature concerning the generation of scholarship, notes that Australia in particular has few research only positions, which has resulted in a dearth of opportunities for experienced nurses to undertake comprehensive research training that includes learning how to write for publication.

In the model of doctoral dissertation by publication or partial publication the research supervisor is also the candidate's writing mentor and co-author of publications submitted. Doctoral dissertation by publication almost always involves co-authorship with the candidate's supervisors. Kamler (2008) found from her study that graduates felt publishing with supervisors enriched their experience of publication, claiming that co-authorship with supervisors is central to understanding the complexity of academic scholarship. In such endeavours however, it is important for supervisors to keep in check both the quantity and quality of their input into higher degree students' publications allowing students' work to be judged and placed on public display. Also as Webb (2008) correctly notes, candidate's decisions about which particular journal to target for publication (Knight \& Steinbach, 2008) should be debated with supervisors, rather than supervisors making such decisions. Supervisors in their role of writing mentor play an important role in supporting students if and when rejection of papers occurs.

We advocate for early publication in the research journey of doctoral candidates. By doing so, writers can reference previous publications and an audit trail of their development of thought is established. As an added incentive for candidates, successful publication of a journal article may result in them receiving additional funds to attend international conferences or to assist with costs associated with their study, for example, the transcription of interview recordings.

\section{The Importance of Planning}

Submitting a doctoral dissertation by full or partial publication is not a task that can be undertaken using an ad hoc approach. It may be tempting to assume that producing a doctoral dissertation in this manner is simply a matter of isolating sections or chapters of the doctoral dissertation as it is produced and submitting these for publication. Approaching the construction of a doctoral dissertation in this manner results in a fragmented document where the absence of forethought is palpable. The return on an investment in planning is a solid and integrated doctoral dissertation. Furthermore, establishment of such focus from the beginning of candidature will avoid the considerable loss of time that can occur when articles are produced that are later found to be extraneous to the central argument of the doctoral dissertation.

The importance of planning cannot be overstated. In the very early stages of candidature, the student and supervisor should develop a strategy for construction of the doctoral dissertation. We have found that production of a table of contents for the doctoral dissertation, highlighting the placement of publications, has proven most effective in enabling candidates to conceptualise how their work will come together. Writing a doctoral dissertation can be extremely challenging and a source of great stress for the candidate (Kamler, 2008). The ability to articulate a draft structure at an early stage can prove motivating for the candidate who is able to visualise as achievable what may otherwise be perceived as a daunting task. The process of writing up the doctoral dissertation 
is reduced from a major single chore to a series of digestible chunks. The result is a greater potential for successful project completion as the student is able to measure his or her progress from the earliest stages.

The process of planning requires consideration of the both structure and content. The onus is not on the examiner to piece together the thought processes of the candidate. Rather, the candidate is obliged to ensure that his or her argument flows logically and that the reader is lead seamlessly through the doctoral dissertation. In so doing the candidate is able to overcome many of the concerns regarding construction of a doctoral dissertation by publication such as those identified by Morse (2005) in the previous discussion. Consideration of a number of practical considerations can ensure success in this regard.

\section{Practical Considerations}

Institutions that permit submission of doctoral dissertation by publication should and often do produce criteria that guide (or in some cases direct) formatting and presentation of the final document. These guidelines can vary from being quite prescriptive in terms of margin width and font style and size, to providing options for preferred formatting only. As with any scholarly piece, attention to such detail enhances the overall quality of the final work.

We have discussed the important role of supervisors as writing mentors and co-authors earlier in this paper. The issue of authorship can be complex in the case of work arising from a doctoral dissertation and may be dictated by institutional policy or disciplinary tradition (Morse, 2009). In many instances, a published piece will have multiple authors and the relative contribution of each author should be disclosed in the doctoral dissertation to provide for appropriate acknowledgement of all who collaborated on a piece of work and also to ensure substantial contribution by the candidate.

Regardless of whether the doctoral dissertation contains a single publication strategically placed or is constructed entirely of published pieces, the doctoral dissertation must be threaded together through the use of introductory and summarising passages that contextualise and link content. As is the case in all forms of scholarly writing, introductions and conclusions frame the discussion, providing clarity in structure and serving as signposts for the reader (Burdess, 2007). The length of these sections may be quite short or of significant length, depending on the extent to which published pieces are relied upon in a given chapter.

Undertaking doctoral research is a dynamic process. Often the study proposed at the outset of the project will evolve in various directions as the candidate explores new territory, encounters obstacles, and develops new insights. It may be necessary when compiling the final doctoral dissertation to explain changes in direction and altered conceptualisations that would not be appropriately discussed in discrete articles. Supportive commentary is therefore not simply decorative, but serves an important purpose in 'pulling' the doctoral dissertation together.

Once the writing is complete, attention is required to assembling the final document. Composition of a doctoral dissertation that contains published articles can be logistically difficult. Skills in the compilation of a doctoral dissertation comprised of documents in different formats (e.g., doc and pdf) are required to facilitate consistency in the final product. Where necessary and available, it may be possible to seek professional editorial assistance to prepare a final document, providing that such assistance is permissible and acknowledged in accordance with the requirements of the conferring institution. 


\section{Examining the Doctoral Dissertation by Publication}

Universities have differing regulations governing the status of the publications within the doctoral dissertation; some mandate that all publications have to be accepted by the publishers, others stipulate that articles can be in a variety of publication stages - accepted, under review, or recently submitted.

Choosing examiners to mark dissertations by publication can be a complex venture. While it is useful for dissemination of a candidate's work to suggest a marker located overseas, not all academics are familiar with the process of submitting a doctoral dissertation by full or partial publication. Marking a higher degree dissertation demands a commitment of time and energy to do justice to the work that students have laboriously created. To examine a doctoral dissertation comprised of pieces of work that have already been subjected to rigorous critique may for some be challenging. For others without experience of marking such work, they may be puzzled about the extent to which they can or cannot comment upon the publications within the work. For the most part, the research office of the university can offer assistance. In our experience examiners of dissertations by publication (of varying formats) are accepting of publications already in print and comment only on those that have been submitted for publication or are in the process of being reviewed by a journal. Such comments have been most useful for candidates when revisions or final production of the relevant articles are required.

The UK Council for Graduate Education published a report by Powell (2004) in which he discusses the issue of examination. He suggests that as well as assessing the doctoral dissertation in a traditional sense the examiners should also:

- appraise the intellectual merit of the publications

- assess the congruence between each publication and their contribution to the whole doctoral dissertation

- review the contribution to new or existing knowledge delineated in each publication

- weigh up the critique of the candidate's own ideas established in each publication

- and, in multi-authored papers, consider the candidate's contribution in terms of percentage and quality of the writing.

To be fair and just to the candidate, examiners have to understand the assessment process as well as knowledge of the candidate's area of research.

\section{Conclusion}

Undertaking doctoral studies can be the most challenging endeavour in a scholarly career. The prospect of further effort to produce publications following conferring of a doctoral degree can often be met with negative perceptions by graduates who feel a sense of writing fatigue. Producing a doctoral dissertation by partial or full publication has enormous benefits, providing that attention is given to ensuring quality of content and structure during all stages of planning and production. The early and widespread dissemination of research outcomes and the ability to contribute to methodological knowledge are examples of such advantages. Candidates profit from peer review throughout their candidature, are spurred on by the achievement of measurable goals, and enhance their professional profile through publishing during their enrolment. We believe that these benefits need not remain purely in the doctorial domain; students undertaking academic programs by research at any level can capitalise on this process from the outset of their study. 


\section{Acknowledgments}

An Australian Government National Health and Medical Research Council Primary Health Care Fellowship funded the work of Dr Jane Mills on this manuscript. NHMRC Grant ID: 431532.

\section{References}

Anders, R., \& Monsivais, D. (2006). Supporting faculty proposal development and publication. Nurse Educator, 31(6), 235-237.

Baldwin, C., \& Chandler, G. (2002). Improving faculty publication output: The role of a writing coach. Journal of Professional Nursing, 18(1), 8-15.

Burdess, N. (2007). Good study. Sydney: Pearson Longman.

Chipman, L. (1998). Managing the new agenda: Implications of the West Review. In M. Kiley \& G. Mullins (Eds.), Quality in postgraduate research: Managing a new agenda. Adelaide: University of Adelaide.

Clare, J., \& Stevens, H. (Eds.). (2003). Writing research: Transforming data into text. Edinburgh: Churchill Livingstone.

Crookes, P. (2002). Developing scholarship in nursing: Steps within a strategy. Journal of Nursing Management, 10, 177-181.

International Committee of Medical Journal Editors (ICMJE) (2008). Uniform requirements for manuscripts submitted to biomedical journals: Writing and editing for biomedical publication. Retrieved 14th November 2008, from http://www.icmje.org

Kamler, B. (2008). Rethinking doctoral publication practices: Writing from and beyond the thesis. Studies in Higher Education, 33(3), 283-294.

Knight, L., \& Steinbach, T. (2008). Selecting an appropriate publication outlet: A comprehensive model of journal selection criteria for researchers in a broad range of academic disciplines. The International Journal of Doctoral Studies, 3, 59-79. Retrieved from http://www.ijds.org/Volume3/IJDSv3p059079Knight84.pdf

Lee, C. (2009). The experience of nursing faculty members enrolled in doctoral study. International Journal of Doctoral Studies, 4, 59-75. Retrieved from http://www.ijds.org/Volume4/IJDSv4p059075Lee255.pdf

Morrison-Beedy, D., Aronowitz, T., Dyne, J., \& Mkandawire, L. (2001). Mentoring students and junior faculty in faculty research: A win-win scenario. Journal of Professional Nursing, 17(6), 291-296.

Morse, J. (2005). Feigning independence: The article dissertation. [Editorial]. Qualitative Health Research, $15,1147-1148$.

Morse, J. (2009). Negotiating authorship for doctoral dissertation publications. Qualitative Health Research, 19(1), 3-4.

Phillips, E., \& Pugh, D. (1994). How to get a PhD: A handbook for students and their supervisors. Buckingham: Open University Press.

Powell, S. (2004). The award of PhD by published work in the UK. Lichfield: UK Council for Graduate Education.

Records, K., \& Emerson, R. J. (2003). Mentoring for research skill development. Journal of Nursing Education, 42(12), 553-557.

Smith, B. (2000). Research training and the conceptual barbarism of the White paper's postgraduate reserach agenda. The Australian Universities' Review, 43(2), 2-4.

Steele, C. (2008, 9 July). We must e-publish or perish. The Australian. Retrieved from http://www.theaustralian.news.com.au/story/0,25197,23989921-25192,00.html 
Timmons, S., \& Park, J. (2008). A qualitative study of the factors influencing the submission for publication of research undertaken by students. Nurse Education Today, 28, 744-750.

Webb, C. (2008). Writing for publication. Retrieved from http://www.nurseauthoreditor.com/WritingforPublicationbooklet2008.pdf

Wills, C., \& Kaiser, L. (2002). Navigating the course of scholarly productivity: The protege's role in mentoring. Nursing Outlook, March/April, 61-66.

\section{Biographies}

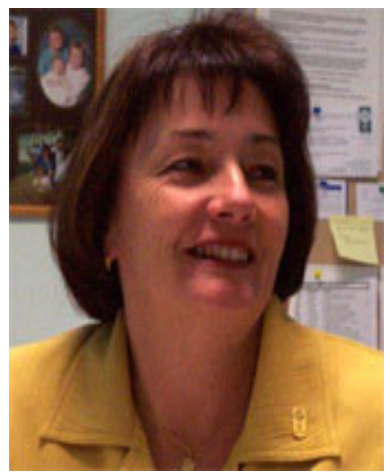

Professor Karen Francis is the Head of the School of Nursing and Midwifery Gippsland Campus and Professor of Rural Nursing. Professor Francis is recognised nationally and internationally for her contribution to the development of the discipline of rural nursing. Her research and publication agendas have focused on exploring the realities of nursing in rural environments, health workforce, preparation for practice, and rural populations' health issues. Professor Francis has served on many state/national committees and participated in forums examining and developing policy and/or guidelines on nursing education and practice. She has supervised to successful completion 28 Doctoral candidates and currently is supervising $12 \mathrm{PhD}$ students. Her methodological expertise is primarily critical interpretative approaches which provide opportunity to explore, describe, critique and augment change when appropriate.

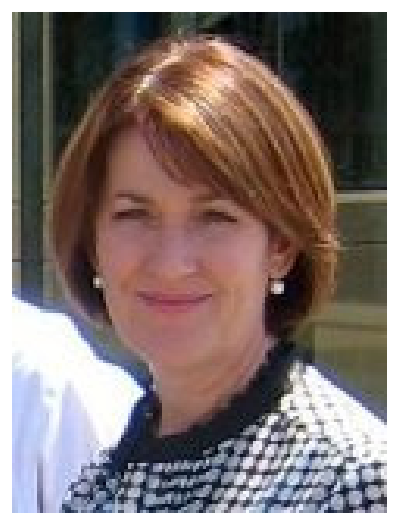

Dr Jane Mills' work as a nurse academic is predominantly as a researcher. Her methodological expertise is in grounded theory; however she also has experience in action research and mixed methods. Dr Mills' research has predominately focused on rural and remote nursing. Her Master of Nursing and $\mathrm{PhD}$ Theses investigated aspects of Australian rural nursing with her doctoral research study exploring Australian rural nurses' experiences of mentoring using constructivist grounded theory research design. She is the Deputy Head of School of Nursing and Midwifery at the James Cook University, Cairns Campus.

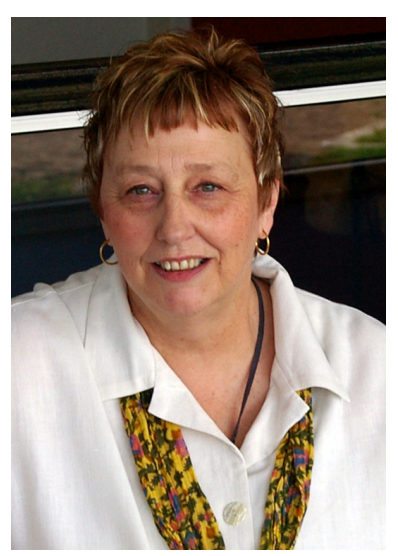

Associate Professor Ysanne Chapman is a senior academic and course coordinator in the School of Nursing and Midwifery, Monash University Gippsland Campus. Her research interests include nursing education, cancer care and rural nursing. She is an experienced research supervisor currently supervising $8 \mathrm{PhD}$ students and 6 Master by Research students. 


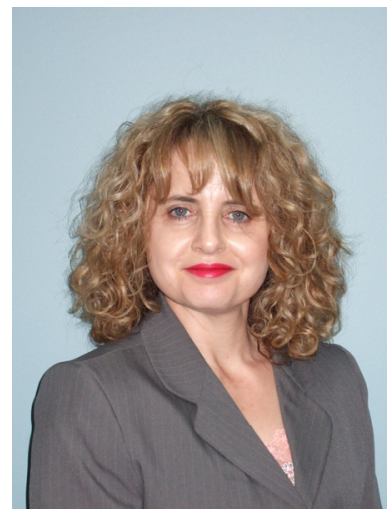

Dr. Melanie Birks is a senior lecturer in the School of Nursing and Midwifery, Monash University Gippsland Campus. She is course coordinator for a post registration degree for registered nurses and teaches in the preservice undergraduate nursing and midwifery programs offered by the School. Dr Birks has postgraduate qualifications in education and her doctoral study examined Malaysian registered nurses experience of undertaking a post registration degree. Her methodological expertise is grounded theory; however she has used mixed methods and case study approaches. Dr Birks' research areas of interest include nursing education, modalities of teaching, rural nursing and chronic illness. 